\title{
Investigations on Manufacturing of Magnesium Alloy Powder by Air Atomization*1
}

\author{
Kenji Date ${ }^{1, * 2}$ and Taku Iwaoka ${ }^{2}$ \\ ${ }^{1}$ Advanced Technology Research and Development Center, Hitachi Chemical Co., Ltd., Matsudo 270-2295, Japan \\ ${ }^{2}$ Tokyo Metropolitan Industrial Technology Research Institute, Tokyo 135-0064, Japan
}

We investigated the possibility of atomizing a molten magnesium $(\mathrm{Mg})$ alloy by air instead of argon gas in order to manufacture the powder at a low cost. As a result, we obtained a powder from a molten $\mathrm{Mg}$ alloy containing yttrium (Y), calcium (Ca) or aluminum (Al) by air atomization without combustion. Each powder had an approximately 100-nm thick oxide film with condensed Y, Ca or Al, which can make the oxide film dense enough to isolate the molten $\mathrm{Mg}$ alloy droplet surface from air. In the case of $\mathrm{Al}, 6$ mass $\% \mathrm{Al}$ or more was required to prevent combustion. Al was also condensed in the matrix near the interface with the oxide film, which can reduce the Mg vapor pressure on the matrix surface under the oxide film. A high cooling rate of the droplet is also effective to prevent combustion. As air-atomized AZX912 powder has the same matrix structures as the argon-gas-atomized one, we expect that the sintered parts of the air-atomized Mg alloy powder can be obtained by breaking the oxide film during the forming and sintering process. [doi:10.2320/matertrans.Y-M2020834]

(Received February 27, 2020; Accepted May 20, 2020; Published August 25, 2020)

Keywords: air-atomized Mg alloy powder, protective oxide film, surface of droplet, solidification, oxidation

\section{Introduction}

Transport equipment, such as vehicles, has been required to be lighter for the improvement of fuel efficiency in order to reduce the emissions of $\mathrm{CO}_{2}$. It is then effective to replace ordinal steels with light metals such as magnesium $(\mathrm{Mg})$ and aluminum (Al) alloys. Especially, $\mathrm{Mg}$ alloys have the lowest specific densities of practical structural metals and higher specific strengths. Recently, Mg alloys with a noncombustibility and greater high-temperature strength were developed by the addition of calcium (Ca), yttrium (Y), etc. ${ }^{1)}$ $\mathrm{Mg}$ alloys also have properties of high damping and electromagnetic wave shielding, which are effective for electronically-controlled equipment. $\mathrm{Mg}$ alloys also have a high recyclability like $\mathrm{Al}$ alloys. ${ }^{2)}$

Meanwhile, the powder metallurgy method has more flexibility in the design of the microstructure and potential to provide better properties than the cast or wrought method. For example, a higher strength and toughness can be obtained due to a fine and uniform microstructure by a rapidly solidified fine raw powder. Moreover, better properties can be obtained due to the design of a microstructure by additives such as a powder or fiber of elemental metals, alloys, ceramics, carbides, etc. ${ }^{3)}$ Functionally graded materials can be also obtained by changing the blending ratio of the additives in a powder compact. In addition, it is suitable for mass production of near net shaped sintered parts. Therefore, we intend to develop $\mathrm{Mg}$ alloys by the powder metallurgy method.

However, molten $\mathrm{Mg}$ alloys are ordinarily highly combustible in air. Therefore, gas atomization, which is suitable for the mass production of metal powders, requires a huge amount of argon (Ar) gas to atomize the molten $\mathrm{Mg}$ alloy without combustion. As the Ar gas price is high, the cost of $\mathrm{Mg}$ alloy powders by Ar atomization becomes too high and limits the industrialization of $\mathrm{Mg}$ alloy sintered

\footnotetext{
${ }^{* 1}$ This Paper was Originally Published in Japanese in J. Jpn. Soc. Powder Powder Metallurgy 66 (2019) 485-492.

${ }^{* 2}$ Corresponding author, E-mail: kenji.date.pv@hitachi-metals.com
}

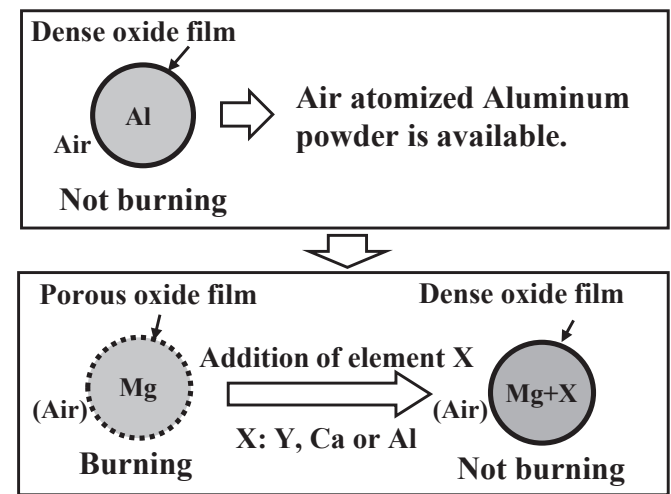

Fig. 1 Method to support incombustibility of air atomized droplet of $\mathrm{Mg}$ alloy.

materials by powder metallurgy. On the contrary, $\mathrm{Al}$ powder is produced at a low cost by air atomization which uses air instead of Ar gas. This is because a thin dense oxide film instantaneously forms on the molten Al surface, isolates the molten $\mathrm{Al}$ from air, and prevents combustion. ${ }^{4)}$ However, the oxide film on the molten $\mathrm{Mg}$ surface is porous and permeable by air. In recent years, it has been reported that a thin dense $\mathrm{CaO}$ film formed on the outermost layer of the oxide film by the addition of $\mathrm{Ca}$ to the $\mathrm{Mg}$ alloys prevents combustion of the molten $\mathrm{Mg}$ alloys. ${ }^{5-7)}$ Therefore, we expected that the addition of certain elements, such as $\mathrm{Ca}, \mathrm{Y}$ and $\mathrm{Al}$, can help a thin dense oxide film form on the surface of the air-atomized droplets, as shown in Fig. 1. The Mg alloy powder can be produced by air atomization and well sintered when the oxide film is thin enough to be broken down during the forming process. This study investigated the effects of the addition of $\mathrm{Y}$ or $\mathrm{Ca}$ and $\mathrm{Al}$ on the air atomization of $\mathrm{Mg}$ alloys.

\section{Experimental Procedure}

\subsection{Procedure of air atomization}

Table 1 summarizes the compositions of the $\mathrm{Mg}$ alloys in this study. Figure 2 and Fig. 3 show schematic diagrams of the procedures to melt the $\mathrm{Mg}$ alloys and atomize them by air, 
Table 1 Compositions of $\mathrm{Mg}$ alloys for air atomization.

\begin{tabular}{ccccccccc}
\hline & & \multicolumn{1}{c}{} & \multicolumn{1}{c}{ (mass \%) } \\
\hline No. 1 & $\mathrm{Mg}_{97} \mathrm{Zn}_{1} \mathrm{Y}_{2}$ & 6.8 & 0.0256 & 0.0621 & 2.5 & 0.0012 & 0.0010 & bal. \\
No. 2 & AZX912 & - & 2.09 & 9.10 & 0.72 & 0.30 & 0.0570 & bal. \\
No. 3 & AZ91D & - & - & 9.09 & 0.72 & 0.30 & 0.0550 & bal. \\
No. 4 & AZ61A & - & - & 6.16 & 0.72 & 0.34 & 0.0360 & bal. \\
No. 5 & AZ31B & - & - & 3.07 & 0.98 & 0.40 & 0.0120 & bal. \\
\hline
\end{tabular}

(a) Ar gas substitution

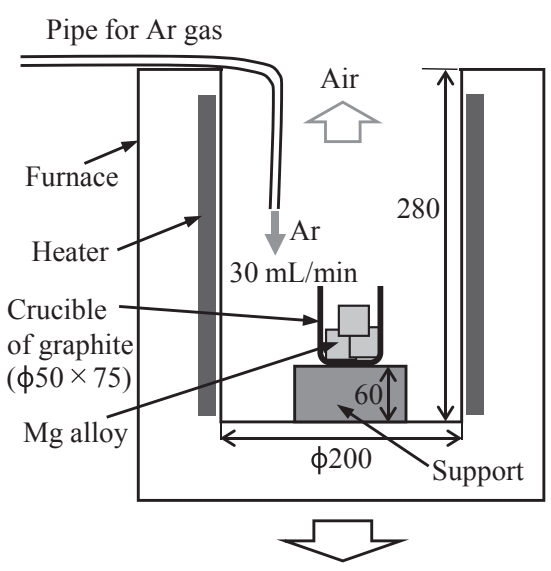

(b) Heating with crucible and furnace closed

Lid of refractory bricks with gap

for Ar gas piping and thermocouple

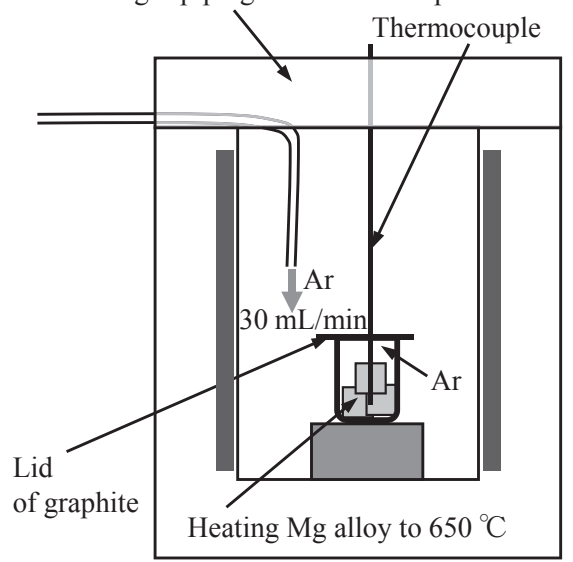

Fig. 2 Schematic diagram of the method to melt Mg alloys.

respectively. Approximately $80 \mathrm{~g}$ of rectangular parallelepiped blocks with a side of approximately 10 to $15 \mathrm{~mm}$ were cut from commercial cast ingots of the Mg alloys (Fuji Light Metal Co., Ltd.) and placed in a graphite crucible with the inner size of approximately $\phi 50 \times 75 \mathrm{~mm}^{3}$. The crucible with the $\mathrm{Mg}$ alloy was placed on a support at the bottom of the furnace with the inner size of approximately $\phi 200 \times 280 \mathrm{~mm}^{3}$, as shown in Fig. 2(a). Ar gas was then introduced into the furnace at $30 \mathrm{~mL} / \mathrm{min}$ to prevent oxidation of the $\mathrm{Mg}$ alloy in the crucible during heating. Because Ar gas is heavier than air, Ar gas substitution starts from the bottom of the furnace. Thus the inside of the
Molten Mg alloy (No. 1 5 (Table 1)) heated to $650{ }^{\circ} \mathrm{C}$ in furnace (Fig. 2)

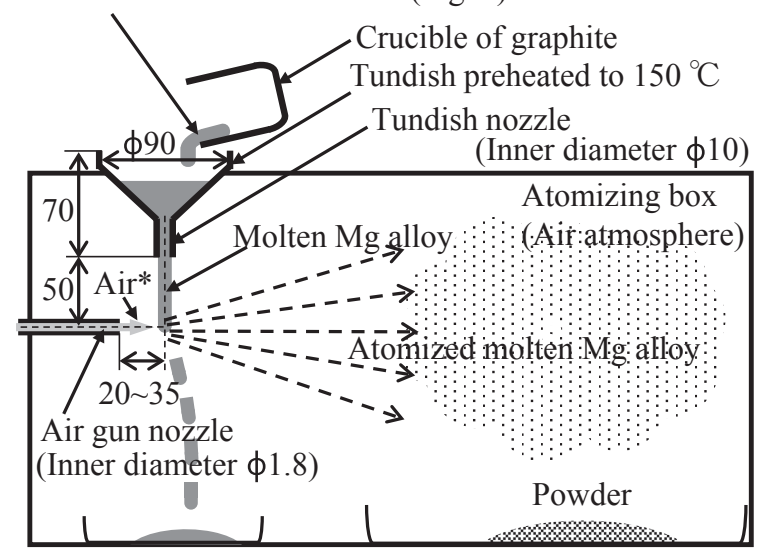

* Pressure of air compressor : $1 \mathrm{MPa}$

Fig. 3 Schematic diagram of the equipment of air atomization.

crucible at the bottom of the furnace was also substituted with the Ar gas at the same time.

After it was confirmed that the fire of a lighter went out in the furnace, the crucible and furnace were closed by a lid of graphite through a thermocouple for the measurement of the $\mathrm{Mg}$ alloy temperature and the lid of two refractory bricks, respectively, as shown in Fig. 2(b), then the heating started. There was almost no gap between the hole in the crucible lid and the thermocouple passing through the hole. However, there was an approximately $10 \mathrm{~mm}$ wide gap between the two bricks of the furnace lid which the Ar gas piping and thermocouple passed through. We observed that the Mg alloy blocks in the crucible severely oxidized during the heating without the crucible lid. The oxidation can be caused by air flowing into the furnace through the gap in the bricks after the heating starts. Thus the crucible lid can isolate the $\mathrm{Mg}$ alloy blocks inside the crucible from the air flowing into the furnace and a little residual oxygen in the crucible can almost be removed due to the preferential oxidation of the graphite crucible and lid material.

The $\mathrm{Mg}$ alloy in the crucible was heated to $650^{\circ} \mathrm{C}$ for $40 \mathrm{~min}$ and held at $650^{\circ} \mathrm{C}$ for $10 \mathrm{~min}$. The crucible with the molten $\mathrm{Mg}$ alloy was removed from the furnace as soon as possible and the molten $\mathrm{Mg}$ alloy was poured into the tundish of the equipment for air atomization in 1 or $2 \mathrm{~s}$, as shown in Fig. 3. The vertical molten $\mathrm{Mg}$ alloy flow from the tundish nozzle with the inner diameter of $\phi 10 \mathrm{~mm}$ was atomized by the horizontal air blowing from the air gun nozzle with the 
inner diameter of $\phi 1.8 \mathrm{~mm}$ under the compressor pressure of $1 \mathrm{MPa}$. The distance between the molten $\mathrm{Mg}$ alloy flow and the tip of air gun nozzle was 20 to $35 \mathrm{~mm}$. The funnel of the stainless steel coated with carbon was used as the tundish, which was preheated at $150^{\circ} \mathrm{C}$ until just before the molten $\mathrm{Mg}$ alloy was poured.

We observed the atomizing behavior of the molten $\mathrm{Mg}$ alloy and collected the atomized powder in the atomizing box to analyze it.

\subsection{Procedures of investigations for air-atomized pow- der}

The powders obtained from $\mathrm{Mg}$ alloys No. 1, No. 2 and No. 3 by air atomization were labeled Powder 1, Powder 2 and Powder 3, respectively. Powders 1 to 3 with a particle size of approximately 100 to $500 \mu \mathrm{m}$ were evaluated in detail. The shapes of the powder particles were observed by scanning electron microscopy (SEM: FEI Quanta200 3D FEG).

The chemical structure, such as the abundance ratio of the elements and the chemical bonding state within approximately $5 \mathrm{~nm}$ from the powder particle surface, was analyzed by X-ray photoelectron spectroscopy (XPS: ULVAC-PHI 5000 Versa Probe II). The flat layer of powder particles which closely adhered to a $10-\mathrm{mm}$ square carbon tape was prepared for the XPS specimen. The X-ray source was monochromated $\mathrm{Al} \mathrm{K} \alpha$ rays, the detecting angle was $45^{\circ}$, and the analyzing area was within a diameter of $200 \mu \mathrm{m}$. The chemical bonding state of $\mathrm{Ca}$ was analyzed by the binding energy peak of $\mathrm{Ca} 2 \mathrm{~s}$ because the binding energy peak of MgKLL and $\mathrm{Ca} 2 \mathrm{p}$ overlapped due to using $\mathrm{Al} \mathrm{K} \alpha$ rays as the $\mathrm{X}$-ray source.

A cross-section of the surface and the proximity of a powder particle was also analyzed. The particle was coated with carbon by vapor deposition to protect the surface and a thin sheet specimen was cut out from the particle surface in the depth direction by focused ion beam (FIB: JEOL JIB4501) under the gallium (Ga) ion accelerating voltage of $30 \mathrm{kV}$. The specimen was observed by scanning transmission electron microscopy (STEM: JEOL JEM-2100F) under the accelerating voltage of $200 \mathrm{kV}$. Elemental mapping and line analysis were performed corresponding to the STEM image by energy dispersive X-ray spectrometry (EDX: JEOL JED2300) to analyze the distribution of elements from the surface oxide layer to the inter matrix of the particle.

Ar-gas-atomized powder, Ref, with the composition listed in Table 2 (Tobata Seisakusho Co., Ltd.), which is the same material as the $\mathrm{Mg}$ alloy No. 2, was also investigated in the same way as Powders 1 to 3 for comparison. In addition, the matrix microstructures in the cross-section of Powder 2 and Ref were observed by optical microscopy (OM: Nikon TME400). The powders were cold embedded with epoxy resin, mirror-polished with $\mathrm{SiC}$ paper and a micro-cloth, and etched with a solution of $5 \mathrm{ml}$ of acetic acid, $5 \mathrm{~g}$ of picric acid, $10 \mathrm{ml}$ of distilled water and $100 \mathrm{ml}$ of ethanol.

\section{Results and Discussion}

\subsection{Observation of air atomizing behavior of molten $\mathrm{Mg}$ alloys}

Figure 4 shows the air atomizing behavior of molten $\mathrm{Mg}$ alloy Nos. 1 to 5. The flow surface of the molten $\mathrm{Mg}$ alloy No. 1 from the tandish nozzle was covered with a brown oxide film. The atomized droplets sometimes sparked, as shown in Fig. 4, but the droplets flew, collided with the walls and floor of the atomizing box, and became a powder without combustion. The melt flowing down to the floor of the box without sufficient atomization formed a pool and solidified with a brown surface without combustion. The atomized droplets of $\mathrm{Mg}$ alloy Nos. 2 to 4 did not spark, solidified and became powders. Molten $\mathrm{Mg}$ alloy Nos. 2 and 3 flowing down to the floor also solidified without combustion. The pool of Mg alloy No. 2 on the floor solidified with a silverwhite surface like its powder. The pool of Mg alloy No. 3 solidified with black spots gradually forming on the silverwhite surface. The pool of $\mathrm{Mg}$ alloy No. 4 solidified with a slight instantaneous flame and changed from a silver-white to black surface. The black area of the solidified pool surface of $\mathrm{Mg}$ alloy Nos. 3 and 4 can be due to severe oxidation. ${ }^{8)}$ The atomized droplets of $\mathrm{Mg}$ alloy No. 5 became black

Table 2 Compositions of argon gas atomized AZX912 powder.

\begin{tabular}{cccccccc}
\hline & & & & & \multicolumn{3}{c}{ (mass \%) } \\
\hline Ref & AZX912 & 1.98 & 9.22 & 0.74 & 0.19 & 0.0003 & bal. \\
\hline
\end{tabular}

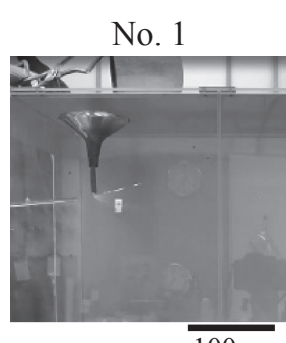

$100 \mathrm{~mm}$
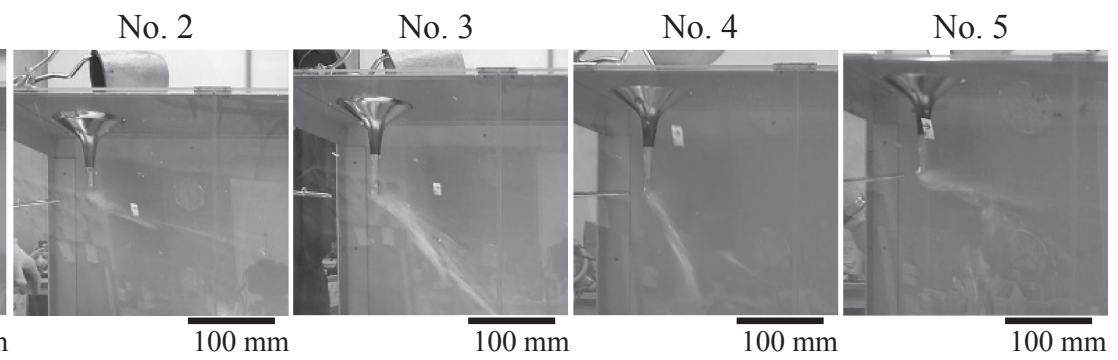

Fig. 4 Appearance of atomizing molten $\mathrm{Mg}$ alloy by air. 
during flight and then severely burned with a flash when they collided with the walls and floor of the atomizing box. The melt flowing down to the floor and attached to the crucible wall also severely burned.

Above all, we obtained the powder from Mg alloy Nos. 1 and 2 containing $\mathrm{Y}$ and $\mathrm{Ca}$, respectively, and $\mathrm{Mg}$ alloy Nos. 3 and 4 containing 6 mass $\% \mathrm{Al}$ or more by air atomization without combustion. The molten $\mathrm{Mg}$ alloy Nos. 3 and 4 flowing down to the floor severely oxidized, but their atomized droplets did not. This is probably because the melt flowing down to the floor solidified more slowly and exposed the surface to a high temperature for a longer time than the atomized droplets.

\subsection{Investigation of air-atomized powder}

\subsubsection{Appearance of powder}

Figure 5(a) shows appearance photos of Powders 1 to 3 as collected in the atomizing box and Fig. 5(b) shows SEM images of Powders 1 to 3 especially with a particle size of approximately 100 to $500 \mu \mathrm{m}$. Figure 6 shows an SEM image of Ref. The fine powder particles were collected with large flakes from Fig. 5(a). Powder 1 exhibited a brown color which was caused by the effect of Y, while Powders 2 and 3 were silver-white. The shapes of Powders 1 to 3 were irregular drop-like while that of Ref was spherical. The oxide film of Powders 1 to 3 by air atomization can be denser than (a)

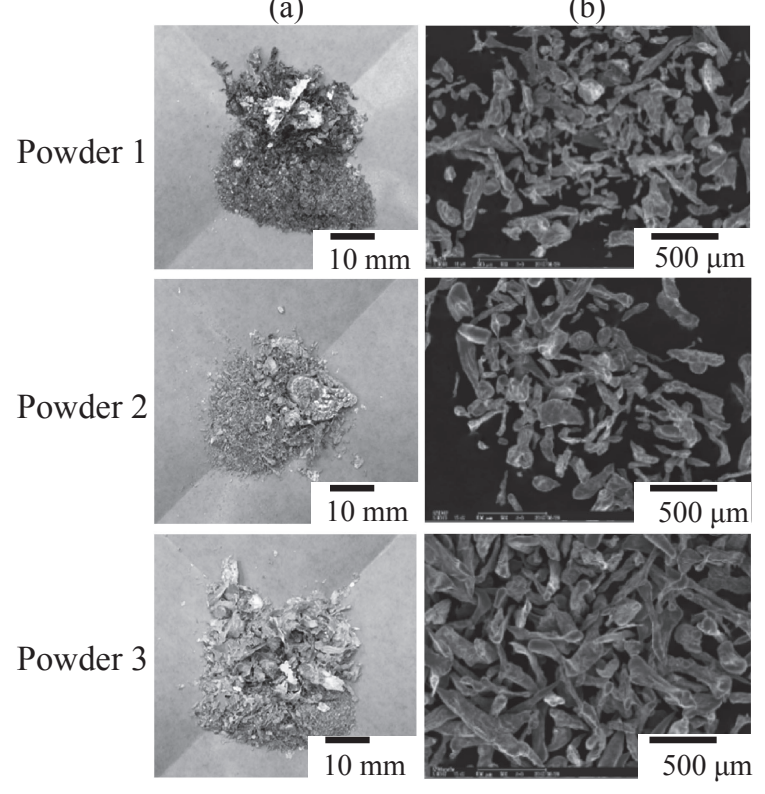

Fig. 5 Air atomized powder of No. 1-3: (a) Appearance, (b) SEM images.

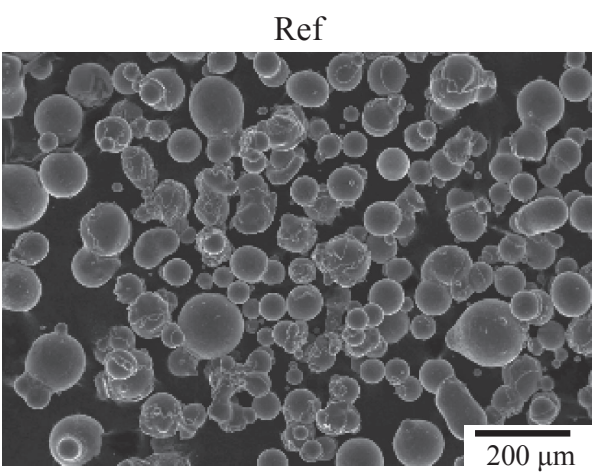

Fig. 6 SEM image of argon gas atomized AZX912 powder (Ref).

that of Ref by the Ar gas atomization and prevent the droplets from becoming spherical due to surface tension. ${ }^{4)}$

\subsubsection{Investigation of the surface and its proximity of powder}

\section{(1) Surface}

Table 3 summarizes the abundance ratio of each element on the surface of Powders 1, 2, 3 and Ref analyzed by XPS. The abundance rate of oxygen $(\mathrm{O})$ of every powder surface was around 50 at $\%$. In Powder 1 , the abundance rate of $Y$ was 12.3 at $\%$, much more than 2 at $\%$ of $\mathrm{Mg}$ alloy No. 1 (converted from 6.8 mass $\%$ in Table 1). Since the Y content of the matrix was regarded as 2 at $\%$, Y was condensed on the surface. The analysis of the chemical bonding state exhibited peaks of the binding energy of $\mathrm{MgO}, \mathrm{MgO}_{\mathrm{X}}(\mathrm{X}<1)$ and $\mathrm{Y}_{2} \mathrm{O}_{3}$, and these oxides existed on the Powder 1 surface. In Powder 2, the abundance rate of $\mathrm{Ca}$ was 4.2 at $\%$, more than 3.3 at $\%$ of $\mathrm{Mg}$ alloy No. 2 (converted from 2.09 mass $\%$ in Table 1) regarded as the Ca content of the matrix. Therefore, $\mathrm{Ca}$ was condensed on the surface, but $\mathrm{Al}$ was not detected as the measurement limit was 0.1 at $\%$ or less, and hardly existed on the Powder 2 surface. The analysis of the chemical bonding state clearly exhibited the binding energy peak of $\mathrm{MgO}$, but not clearly $\mathrm{CaO}$. Thus $\mathrm{Ca}$ existed as $\mathrm{CaO}$ or a solid solution component in $\mathrm{MgO}$ on the surface. In Powder 3, the analysis results exhibited the bonding energy peak of $\mathrm{MgO}$ and $\mathrm{MgO}_{\mathrm{X}}(\mathrm{X}<1)$ and $\mathrm{Al}$ was not detected like on the Powder 2 surface. Therefore, $\mathrm{Mg}$ oxides existed and $\mathrm{Al}$ hardly existed on the Powder 3 surface. In addition, the binding energy peak of $-\mathrm{CO}_{3}$ was detected in Powders 1 to 3 . The carbonate also existed on the surface of Powders 1 to 3 . It can form as a common corrosion product in the ambient atmosphere. ${ }^{9)}$

On the other hand, in Ref, the abundance rate of $\mathrm{Ca}$ and $\mathrm{Al}$ were 1.0 at $\%$ and 2.1 at\%, respectively, while the $\mathrm{Ca}$ and $\mathrm{Al}$

Table 3 Abundance ratio of elements on the surface of No. 1-3 and Ref powder.

\begin{tabular}{cccccccc}
\hline & \multicolumn{1}{c}{} & \multicolumn{1}{c}{} & & (at \%) \\
\hline Powder 1 & 12.3 & - & - & 9.8 & 54.2 & 23.7 & Ar \\
Powder 2 & - & 4.2 & - & 19.1 & 47.1 & 29.6 & - \\
Powder 3 & - & - & - & 26.7 & 51.9 & 21.4 & - \\
Ref & - & 1.0 & 2.1 & 24.9 & 55.8 & 14.2 & 1.9 \\
\hline
\end{tabular}


contents in its matrix were regarded as 1.2 at $\%$ and 8.5 at $\%$ from the Ref composition (converted from 1.98 mass $\%$ and 9.22 mass $\%$ in Table 2, respectively). Thus Ca was not condensed and Al clearly existed at the surface. Those are different from Powder 2 with a composition similar to Ref. The analysis of the chemical bonding state showed that $\mathrm{Mg}$ mainly existed as $\mathrm{Mg}(\mathrm{OH})_{2}$, but not $\mathrm{MgO}$, and $\mathrm{Al}$ mainly existed as metal $\mathrm{Al}$ and $\mathrm{Al}(\mathrm{OH})_{3}$. The $-\mathrm{CO}_{3}$ binding energy was also detected. Thus the components on the surface were mainly carbonate and hydroxide, which can be formed by the reaction of the powder surface with the ambient atmosphere. As a result, the abundance rate of $\mathrm{O}$ became as high as that of the air-atomized powder. The droplet of Ref cannot oxidize during atomization and solidification because of its spherical particle shape. ${ }^{4}$ In addition, Ar was also detected, which can penetrate into the droplet during the atomization.

Above all, on the surface of the air-atomized powder, Al did not virtually exist and $\mathrm{Y}$ and $\mathrm{Ca}$ condensed. $\mathrm{Y}$ existed as $\mathrm{Y}_{2} \mathrm{O}_{3}$ and $\mathrm{Ca}$ existed as $\mathrm{CaO}$ or a solid solution component in $\mathrm{MgO}$. On the other hand, on the surface of the Ar-gasatomized powder, $\mathrm{Al}$ existed and $\mathrm{Ca}$ was not condensed. Therefore, the abundance rate of these elements at the surface can be affected by the extent of oxidation of the droplet surface during the atomization and solidification. During the air atomization, $\mathrm{Ca}$ and $\mathrm{Mg}$ can migrate faster to the surface to oxidize than $\mathrm{Al}$ because $\mathrm{Ca}$ and $\mathrm{Mg}$ oxidize easier than $\mathrm{Al}$. As a result, Al disappeared on the surface. However, during the Ar gas atomization, each element near the droplet surface cannot migrate to the surface, where the oxidation cannot occur during atomization and solidification. Therefore, Al remained at the surface and $\mathrm{Ca}$ was not condensed.

\section{(2) Cross-section of surface and its proximity}

Figure 7 and Fig. 8 show the results of the elemental mapping and the line analysis of a cross-section of the surface and its proximity of Powders 1, 2, 3 and Ref, respectively. The line analysis was performed with a width of $200 \mathrm{~nm}$ centered on the dotted line as shown in the STEM images. Since the specimen thickness was approximately $100 \mathrm{~nm}$ and the oxide film of the particle surface was not a vertical plane to the observation surface and the analysis line, the distribution of each element did not exhibit a clear discontinuity at the powder surface and the interface between the oxide film and the matrix. Moreover, the absolute value of each elemental intensity was impossible to compare among Powders 1, 2, 3 and Ref due to the differences in their composition and specimen thickness.

Powder 1 had a black layer at the particle surface based on the STEM image, where $\mathrm{O}$ and $\mathrm{Y}$ were condensed from the elemental mapping, as shown in Fig. 7. The $\mathrm{O}$ peak

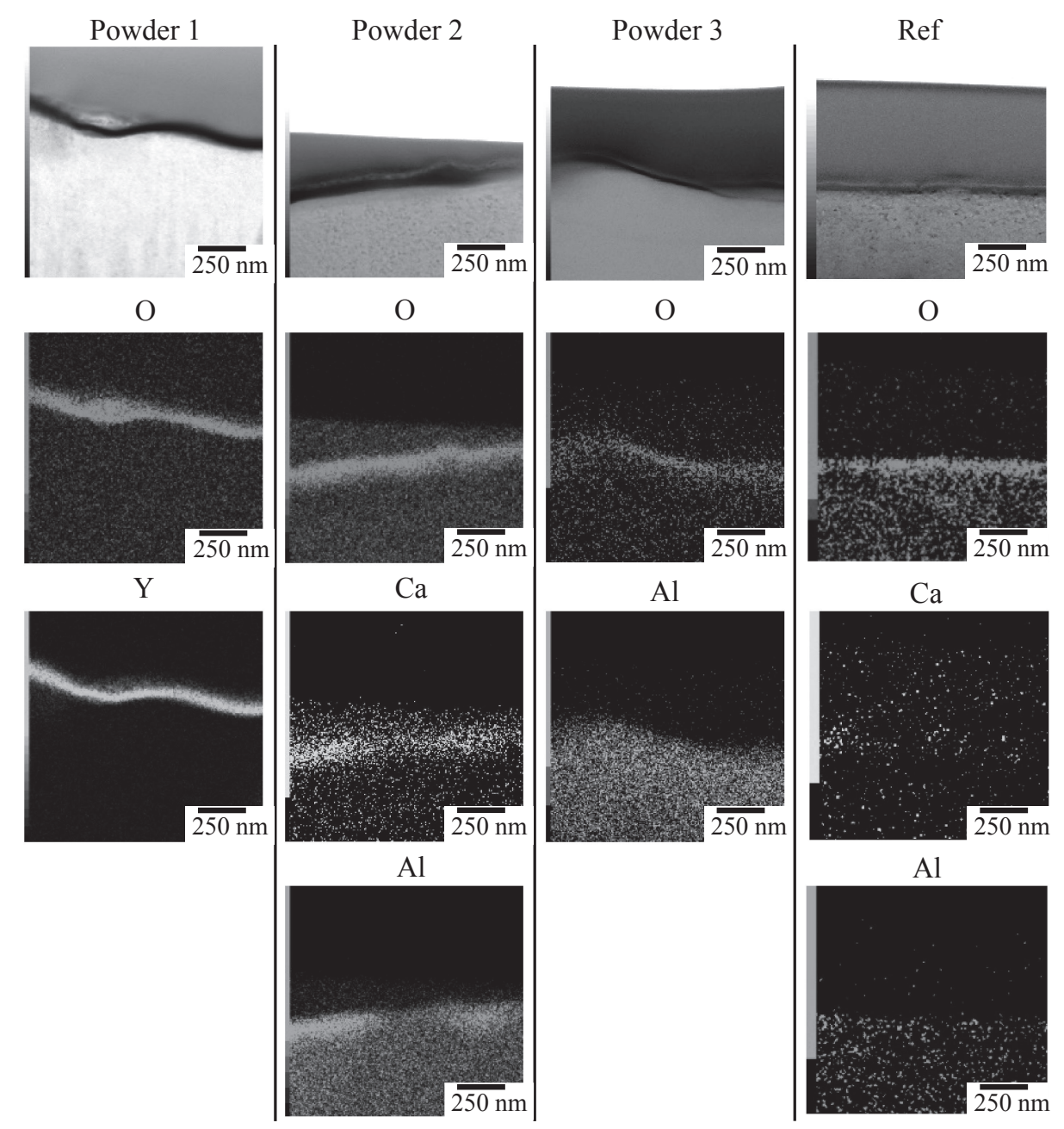

Fig. 7 STEM-EDX element mapping of cross section near the surface of No. 1-3 and Ref powder. 
Powder 1

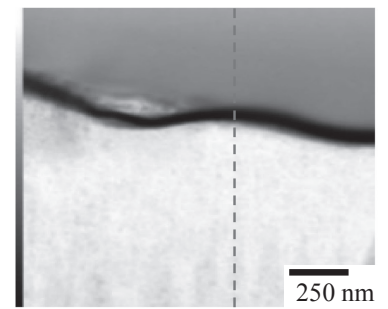

Powder 2

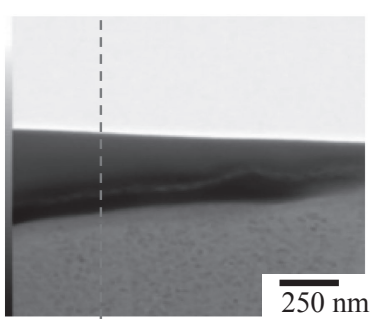

Powder 3

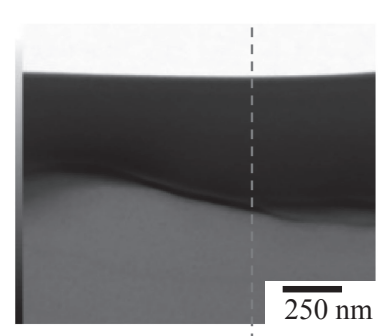

Ref

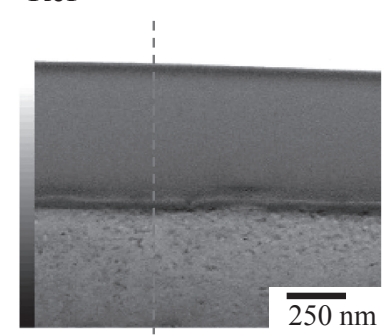

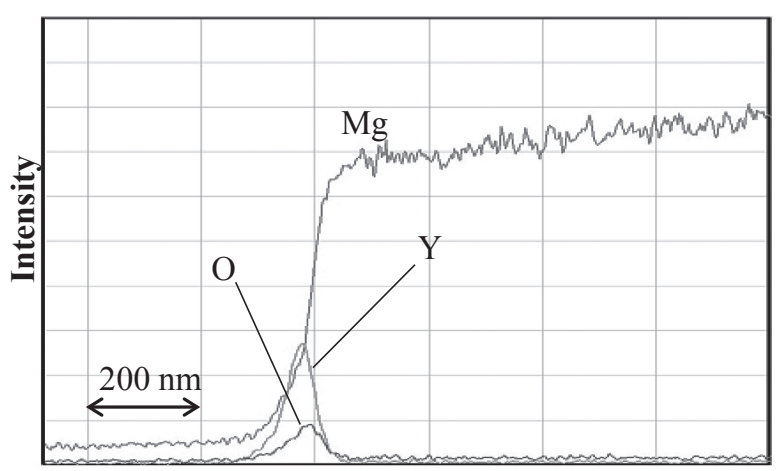

(Surface side)

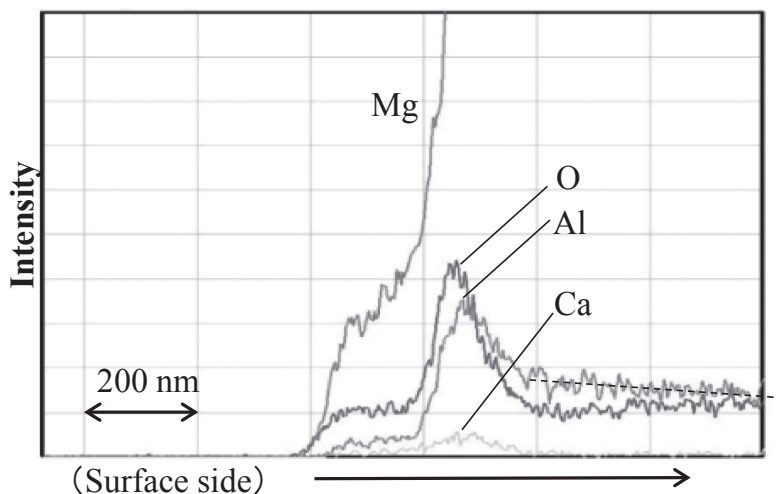

(Surface side)
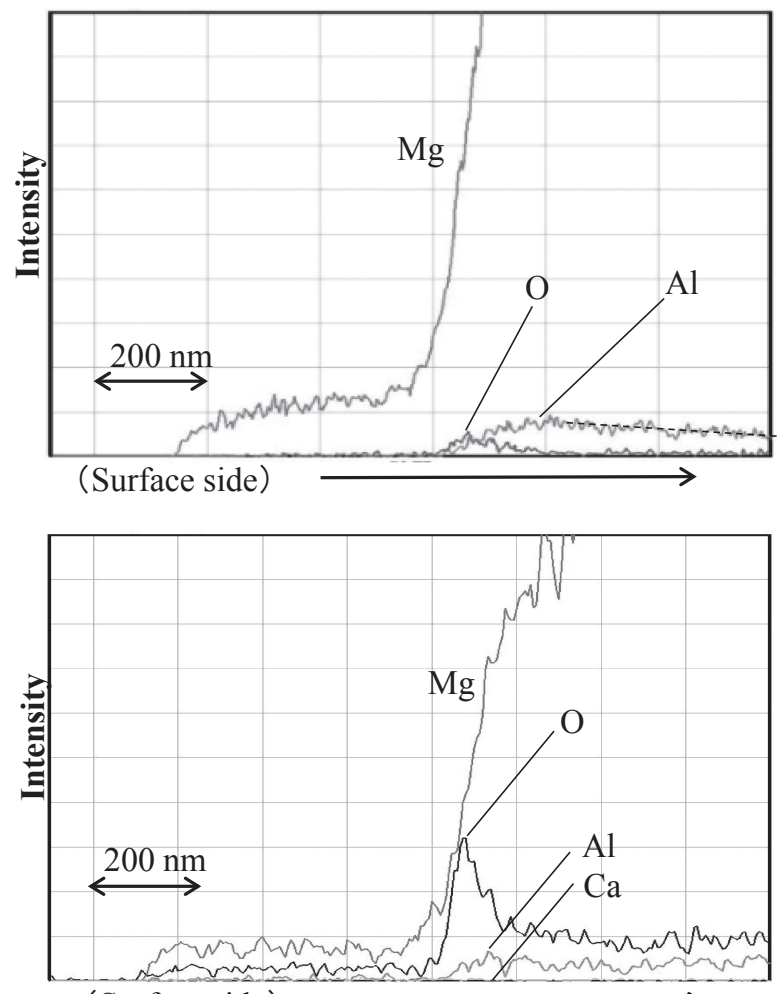

(Surface side)

Fig. 8 Element distribution in the depth direction of No. 1-3 and Ref powder.

corresponding to the oxide film overlapped the Y peak from Fig. 8. Thus, the oxide film with a thickness of 50 to $70 \mathrm{~nm}$ formed at the surface of the particle and contained $\mathrm{Y}_{2} \mathrm{O}_{3}$ based on the XPS results. In addition, the interface between the oxide film and the matrix was clearer than those of Powders 2, 3 and Ref. Powder 2 had an oxide film with a thickness of approximately $130 \mathrm{~nm}$ at the particle surface, where $\mathrm{Ca}$ and $\mathrm{Al}$ were condensed from Fig. 7. Since Al had the peak shifted inward of the particle from those of $\mathrm{O}$ and $\mathrm{Ca}$ as shown in Fig. 8 and was not detected by XPS, the distribution of Al was entirely shifted inward from those of $\mathrm{O}$ and $\mathrm{Ca}$. In addition, the $\mathrm{Al}$ content in the matrix gradually decreased from the interface to the inside. Powder 3 had an oxide film with a thickness of approximately $70 \mathrm{~nm}$ at the 
surface of the particle from Fig. 7. The Al peak was broad and shifted inward from the $\mathrm{O}$ peak as shown in Fig. 8. Moreover, the Al peak top was located at the inner end of the $\mathrm{O}$ peak which corresponded to the interface between the oxide film and the matrix. Therefore, $\mathrm{Al}$ was condensed on both sides of the interface. Since Al had the peak shifted inward from that of $\mathrm{O}$ and was not detected by XPS, the distribution of $\mathrm{Al}$ was entirely shifted inward from $\mathrm{O}$ like Powder 2. Ref had no $\mathrm{Ca}$ and $\mathrm{Al}$ condensation in the high $\mathrm{O}$ content region of approximately $60 \mathrm{~nm}$ at the particle surface unlike Powder 2, as shown in Fig. 7. Ca and $\mathrm{Al}$ were constant from the surface to the inside of the particle regardless of the $\mathrm{O}$ peak at the surface from Fig. 8 . Therefore, the high $\mathrm{O}$ region was probably the corrosion products by the ambient atmosphere, such as carbonate and hydroxide, from the XPS results, but not the oxide film formed during the Ar gas atomization.

Above all, $\mathrm{Y}, \mathrm{Ca}$ and $\mathrm{Al}$ were condensed in the oxide film at the air atomized powder particle surface and the distribution of $\mathrm{Al}$ was shifted entirely inward from the $\mathrm{O}$ and $\mathrm{Ca}$. Thus, $\mathrm{Mg}$ and $\mathrm{Ca}$ probably migrated to the surface over $\mathrm{Al}$ due to the preferential oxidation of $\mathrm{Mg}$ and $\mathrm{Ca}$. Moreover, the $\mathrm{Al}$ condensation was also recognized in the matrix near the interface with the oxide film. When the $\mathrm{Mg}$ alloy contained both $\mathrm{Al}$ and $\mathrm{Ca}, \mathrm{Al}$ condensed more in the oxide film with $\mathrm{Ca}$. $\mathrm{Al}$ was probably attracted to $\mathrm{Ca}$ and migrated to the surface due to the high affinity of $\mathrm{Ca}$ for Al. ${ }^{10,11)}$ It is reported that the $\mathrm{CaO}$ layer formed on the outermost layer of the oxide film and $\mathrm{MgO}$ layer formed just under the $\mathrm{CaO}$ layer when the molten $\mathrm{Mg}$ alloy containing $\mathrm{Ca}$ was held over its melting point in the ambient atmosphere. ${ }^{5-7)}$ Thus, the Ca peak top existed at the outmost surface outward from the $\mathrm{O}$ peak top. ${ }^{6}$ However, in this study, the distribution of $\mathrm{Ca}$ and $\mathrm{O}$ showed the same behavior. This is because the cooling rate of the atomized droplet can be very fast and $\mathrm{Ca}$ cannot sufficiently migrate to form the $\mathrm{CaO}$ layer on the outermost surface. In other words, the oxide film was in a non-equilibrium state.

We concluded that the condensation of $\mathrm{Y}, \mathrm{Ca}$ and $\mathrm{Al}$ in the oxide film of the powder particle surface is effective for suppressing the burning of droplets during the air atomization. Furthermore, the structural analysis by TEM and electron diffraction (ED) should be performed for the oxide films.

\subsection{Estimation mechanism of combustion suppression}

\section{(1) Effects of $\mathrm{Y}, \mathrm{Ca}$ and $\mathrm{Al}$ on oxide film}

The Pilling-Bedworth ratio, $\mathrm{R}_{\mathrm{PB}}\left(=\mathrm{V}_{\text {oxide }} / \mathrm{V}_{\text {metal }}\right)$, which is the ratio of the oxide volume per $1 \mathrm{~mol}$ of the metal element constituting the oxide $\left(\mathrm{V}_{\text {oxide }}\right)$ to the base metal volume per mole $\left(\mathrm{V}_{\text {metal }}\right)$, is often used for the estimation of the denseness and protectivity of the oxide film and it is suggested that $1<\mathrm{R}_{\mathrm{PB}}<2$ is appropriate. The $\mathrm{R}_{\mathrm{PB}}$ of the $\mathrm{MgO}$ film for the $\mathrm{Mg}$ alloy is $0.77,{ }^{7}$ ) which is less than 1 $\left(\mathrm{V}_{\text {metal }}>\mathrm{V}_{\text {oxide }}\right)$, and a porous oxide film composed of fine grains was formed. ${ }^{5)}$ The effect of $\mathrm{Y}, \mathrm{Ca}$ and $\mathrm{Al}$ on the denseness of the $\mathrm{Mg}$ oxide film was evaluated by using the physical properties of the oxide at room temperature. It is postulated that $\mathrm{V}_{\text {metal }}$ cannot significantly change by the composition of the $\mathrm{Mg}$ alloy.
In the oxide film where $\mathrm{MgO}$ exists with $\mathrm{Y}_{2} \mathrm{O}_{3}, \mathrm{CaO}$, $\mathrm{Al}_{2} \mathrm{O}_{3}$ or $\mathrm{MgAl}_{2} \mathrm{O}_{4}$, the $\mathrm{V}_{\text {oxide }}$ of $\mathrm{MgO}, \mathrm{Y}_{2} \mathrm{O}_{3}, \mathrm{CaO}, \mathrm{Al}_{2} \mathrm{O}_{3}$ and $\mathrm{MgAl}_{2} \mathrm{O}_{4}$ were $11.0,22.5,16.8,12.7$ and $13.2 \mathrm{~cm}^{3} / \mathrm{mol}$ respectively, then the $\mathrm{V}_{\text {oxide }}$ of $\mathrm{Y}_{2} \mathrm{O}_{3}, \mathrm{CaO}, \mathrm{Al}_{2} \mathrm{O}_{3}$ and $\mathrm{MgAl}_{2} \mathrm{O}_{4}$ are greater than that of $\mathrm{MgO}$. Therefore, the oxide film of $\mathrm{MgO}$ with $\mathrm{Y}_{2} \mathrm{O}_{3}, \mathrm{CaO}, \mathrm{Al}_{2} \mathrm{O}_{3}$ or $\mathrm{MgAl}_{2} \mathrm{O}_{4}$ can become denser than the single phase $\mathrm{MgO}$ film. Here, $\mathrm{V}_{\text {oxide }}$ was calculated by the following equation: $\mathrm{V}_{\text {oxide }}=\mathrm{M} / \rho / \mathrm{z}$, where $\mathrm{M}$ and $\rho$ are the molar mass and the density of the oxide, respectively, and $\mathrm{z}$ is the number of metal atoms constituting the oxide. For $\mathrm{Ca}$ dissolved in the $\mathrm{MgO}$ to form a composite oxide, the ionic radius of $\mathrm{Ca}^{2+}$ is $114 \mathrm{pm}$, which is larger than the $86 \mathrm{pm}$ of $\mathrm{Mg}^{2+}{ }^{12)}$ Therefore, the oxide film can become denser.

Meanwhile, the oxide film of the molten Mg alloy No. 1 can have a greater denseness and higher compressive stress than the other alloys because the $\mathrm{V}_{\text {oxide }}$ of $\mathrm{Y}_{2} \mathrm{O}_{3}$ is very high. In addition, the oxide film interface with the matrix was clearer. Thus, the bond between the oxide and matrix can be weak. The oxide film on the melt can be easily broken by a large deformation. For this reason, it is postulated that the spark was sometimes observed during atomizing molten $\mathrm{Mg}$ alloy No. 1. However, the combustion did not occur during atomization because a new dense oxide film can form on the melt surface immediately after being broken.

\section{(2) Effects of $\mathrm{Al}$ on combustion suppression}

$\mathrm{Al}$ in the $\mathrm{Mg}$ alloy has the effect of lowering the vapor pressure of $\mathrm{Mg},{ }^{13)}$ and the effect of suppressing the combustion can become lower as the Al content decreases. Therefore, Mg alloy No. 5 with 3 mass $\%$ Al severely burned during atomization, but $\mathrm{Mg}$ alloy Nos. 3 and 4 with 9 and 6 mass \% Al, respectively, did not burn. On the other hand, as described in section 3.2.2 (2), the condensation of $\mathrm{Al}$ in Powder 3 was observed in the oxide film and the matrix near the interface. Al condensed in the oxide film can contribute to the densification of the oxide film as described in section 3.3 (1). Moreover, Al condensed in the matrix near the interface can also suppress the combustion of the droplets by lowering the vapor pressure of $\mathrm{Mg}$ on the matrix surface under the oxide film.

In addition, as described in section 3.1, the cooling rate can be effective in suppressing the combustion. Thus, as the cooling rate of the air atomized droplet increases, the lower limit of the $\mathrm{Al}$ content required to prevent combustion can decrease.

\subsection{Matrix microstructure of powder particle}

Figure 9 shows optical micrographs of the matrix microstructures of the Powder 2 and Ref particles. Powder 2 and Ref were the same alloy of AZX912 and atomized by air and Ar gas, respectively. The matrix microstructures had the same dendrite structures, regardless of the gas type used for the atomization.

We believe the air-atomized $\mathrm{Mg}$ alloy powder can sinter by breaking down the oxide film and ensuring mass transfer between the adjacent particles like the air-atomized $\mathrm{Al}$ powder. For example, the pulse current pressure sintering (PCPS) method can be effective in breaking down the oxide film due to the high shear stress on the particles at a high temperature and pressure. ${ }^{14,15)}$ 

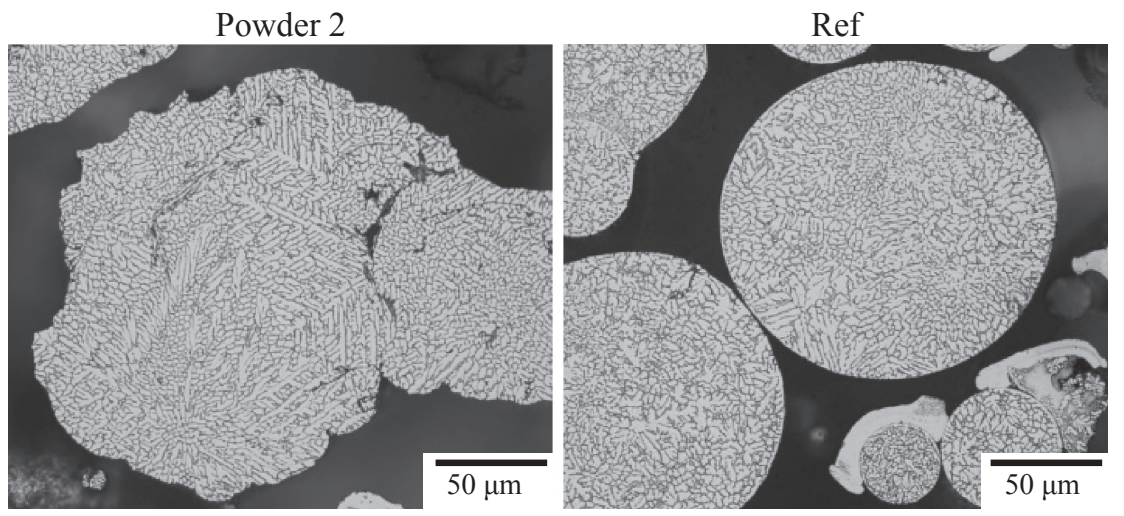

Fig. 9 Optical micrographs of the cross section of powder of No. 2 (air atomized) and Ref (argon gas atomized).

\section{Conclusion}

(1) The powders of $\mathrm{Mg}_{97} \mathrm{Zn}_{1} \mathrm{Y}_{2}$ and AZX912 containing Y and $\mathrm{Ca}$, respectively, and the powders of AZ91 and AZ61 containing 6 mass $\%$ or more of $\mathrm{Al}$ were obtained by air atomization without combustion in this study.

(2) In the Mg alloy powders containing $\mathrm{Y}, \mathrm{Ca}$ or $\mathrm{Al}$, it was confirmed that these elements were condensed in the oxide film. As a result, the oxide film can become denser and suppress the combustion of the atomized droplets.

(3) In the $\mathrm{Mg}$ alloy powders containing $\mathrm{Al}, \mathrm{Al}$ was also condensed in the matrix near the interface with the oxide film. As a result, the $\mathrm{Mg}$ vapor pressure of the matrix surface can decrease and suppress the combustion of the droplets.

(4) The oxide film of the droplets did not have a singlephase $\mathrm{CaO}$ layer, unlike that of the molten metal held over the melting point. Ca cannot sufficiently migrate to the surface to form a $\mathrm{CaO}$ layer due to the high cooling rate of the droplets.

(5) The higher cooling rate can be more effective to prevent the combustion of the air-atomized droplets of the $\mathrm{Mg}$ alloy.

(6) The air-atomized powder had the same internal microstructure as the Ar-gas-atomized powder. We expected that the air-atomized powder can sinter by breaking down the oxide film during the forming and sintering.

\section{REFERENCES}

1) Y. Kawamura: Alutopia (8) (2012) 9-13 (in Japanese).

2) The Japan Magnesium Association: Genba de ikasu kinzokuzairyou siriizu Magnesium, (Maruzen Publishing, Tokyo, 2011) p. 33 (in Japanese).

3) H. Watanabe, N. Ikeo and T. Mukai: J. JILM 66 (2016) 318-323 (in Japanese).

4) I. Murakami, A. Tanaka and K. Higashimura: Alutopia (10) (2012) 3337 (in Japanese).

5) M. Sakamoto, S. Akiyama, T. Hagio and K. Ogi: J. JFS 69 (1997) 227233 (in Japanese).

6) K. Kitayama, H. Kawabata, H. Kato, K. Hibi, Y. Yagi and Y. Aoki: Proceedings of Spring Meeting of the Institute of Light Metals, (2017) 31-32 (in Japanese).

7) S. Inoue, M. Yamasaki and Y. Kawamura: Proceedings of Autumn Meeting of the Institute of Light Metals, (2017) 51-52 (in Japanese).

8) H. Kawabata, H. Kato, K. Kitayama, K. Hibi, Y. Yagi and Y. Aoki: Proceedings of Spring Meeting of the Institute of Light Metals, (2017) 29-30 (in Japanese).

9) S.P. Cashion, N.J. Ricketts and P.C. Hayes: J. Light Met. 2 (2002) 3742.

10) S. Kim, J. Lee, M. Choi and J. Seo: JP P2011-104655A (in Japanese).

11) K. Enami, S. Ono, M. Ohara and T. Igarashi: JP WO2009/113581A1 (in Japanese).

12) The Chemical Society of Japan: Kagaku Binran Kisohen, 5th ed., (Maruzen Publishing, Tokyo, 2004) II-887 (in Japanese).

13) M. Ikeda: Bulletin of Faculty of Engineering, Toyama University 12 (1961) 102-109 (in Japanese).

14) T. Nagae, M. Yokota, M. Nose, S. Tomida, T. Kamiya and S. Saji: J. Japan Inst. Metals. 65 (2001) 726-733 (in Japanese)

15) G. Xie, O. Ohashi, T. Yoshioka, M. Song, K. Mitsuishi, H. Ysuda, K. Furuya and T. Noda: Mater. Trans. 42 (2001) 1846-1849. 